\title{
Easter microplate dynamics
}

\author{
M. C. Neves, ${ }^{1}$ R. C. Searle, and M. H. P. Bott \\ Department of Geological Sciences, University of Durham, Durham, UK
}

Received 8 August 2001; revised 31 October 2002; accepted 31 January 2003; published 23 April 2003.

[1] We use two-dimensional elastic finite element analysis, supplemented by strength estimates, to investigate the driving mechanism of the Easter microplate. Modeled stresses are compared with the stress indicators compiled from earthquake focal mechanisms and structural observations. The objective is to constrain the tectonic forces that govern the Easter microplate rotation and to test the microplate driving hypothesis proposed by Schouten et al. [1993]. We infer that the mantle basal drag cannot drive the microplate rotation but opposes it, and that the asthenospheric viscosity is no more than about $1 \times 10^{18} \mathrm{~Pa}$ s. At most, the basal drag comprises $20 \%$ of the force resisting microplate rotation. The outward pull of the main plates can drive the rotation by shear drag applied along the northern and southern boundaries of the microplate. However, we propose an additional driving force which arises from the strong variation of the ridge resistance force along the east and west rifts, so that the main driving torques come from the pull of the major plates acting across the narrowing and slowing rifts. This requires the strength to increase substantially toward the rift tips due to thickening of the brittle lithosphere as the spreading rate slows. INDEX TERMS: 8120 Tectonophysics: Dynamics of lithosphere and mantle - general; 8155 Tectonophysics: Plate motions - general; 8164 Tectonophysics: Stresses - crust and lithosphere; 3040 Marine Geology and Geophysics: Plate tectonics $(8150,8155,8157$, 8158); 8159 Tectonophysics: Rheology — crust and lithosphere; KEYWORDS: microplate, stresses, strength, oceanic lithosphere, asthenosphere viscosity

Citation: Neves, M. C., R. C. Searle, and M. H. P. Bott, Easter microplate dynamics, J. Geophys. Res., 108(B4), 2213, doi:10.1029/2001JB000908, 2003.

\section{Introduction}

[2] Easter microplate, located near $23^{\circ} \mathrm{S}$ on the East Pacific Rise, is probably the best documented active microplate. Identified by Herron [1972] and Forsyth [1972], its existence was soon connected with the Easter hot spot and with the extremely high spreading velocities in the East Pacific Rise [Anderson et al., 1974]. More recent studies including analysis of earthquake focal mechanisms [Engeln and Stein, 1984], SeaMARC II and GLORIA long-range sidescan data, SeaBeam, and magnetic profiling data [Hey et al., 1985; Francheteau et al., 1988; Searle et al., 1989; Martinez et al., 1991; Naar and Hey, 1991; Rusby and Searle, 1995] revealed in detail Easter microplate tectonics and evolution.

[3] The large amount of acquired data has been used to test models of deformation in ridge overlap systems [Engeln et al., 1988]. Although an initial stage of internal deformation is not excluded, plate reconstructions based on Easter microplate magnetic and structural evidence favor a model of rigid behavior [Naar and Hey, 1991; Rusby and Searle, 1995]. Assuming this rigid behavior, Schouten et al. [1993]

\footnotetext{
${ }^{1}$ Now at Centro de Investigação Marinha e Ambiental, Faculdade de Ciências do Mar e do Ambiente, Universidade do Algarve, Faro, Portugal.

Copyright 2003 by the American Geophysical Union. 0148-0227/03/2001JB000908\$09.00
}

proposed a kinematic model for microplates, known as the "roller bearing" model, which they applied not only to Easter but also to the Galapagos [Lonsdale, 1988] and Juan Fernandez microplates [Larson et al., 1992].

[4] According to the roller bearing model the microplate rotates as a rigid block between plates moving in opposite directions. When the coupling between the microplate and the two bounding plates is perfect, two points at the boundaries (which are the instantaneous poles of rotation of the microplate relative to the main plates) are instantaneously fixed to the main plates. The basic postulate of this model is that the microplate is driven at the instantaneous points of contact by the pull of the main plates.

[5] Lithospheric block rotation driven by an edge mechanism has previously been proposed by McKenzie and Jackson [1983, 1986] to explain how distributed deformation, common in continental regions, is related to the relative motions between major bounding plates. They showed that the rotation rate for an edge-driven model is twice the rotation rate for a floating block embedded in a deforming fluid. Therefore edge-driven models are more appropriate to describe fast rotations about vertical axes, such as that at Easter microplate.

[6] The edge-driven, or roller bearing, model predicts that the rotation rate of the microplate is equal to the spreading rate of the major plates divided by the distance between the instantaneous rotation poles. This relation is in good agreement with the present distance between Easter microplate 
instantaneous rotation poles (about $610 \mathrm{~km}$ ) and the present rotation rate of $15^{\circ}-18^{\circ} \mathrm{Myr}$, derived from the magnetic anomaly data [Naar and Hey, 1991; Rusby and Searle, 1995; Cogné et al., 1995]. Nevertheless, the present instantaneous poles of Pacific-Easter and Nazca-Easter motion lie $50 \mathrm{~km}$ away from the microplate boundaries and not actually on them [Rusby and Searle, 1995]. This implies there is some degree of decoupling between the microplate and the major plates. Also, the plate reconstructions show that the instantaneous poles of rotation have been fixed with respect to the main plates, and thus have not moved with the rift tips through time as the model predicts. This implies that the pseudofaults do not trace the trajectories of the Euler poles, but only the path of the propagating rift tips.

[7] Despite its limitations the roller bearing model provides a first-order description of the kinematics of microplates, especially of Easter and Juan Fernandez [Searle et $a l ., 1993]$. However, the model has never been tested from a dynamic point of view. Here we use Easter microplate as a representative example to analyze the dynamic implications of the roller bearing model. Two complementary hypotheses are considered: the Schouten et al. [1993] hypothesis, where the driving forces for the microplate rotation are shear forces acting along the northern and southern boundaries of the microplate; and the rift-driven hypothesis, where the driving forces are due to the ridge resistance gradient along the East and West Rifts (Figure 1).

[8] At the scale of the large tectonic plates, the direction of maximum horizontal stress approximately follows the direction of absolute plate motions, suggesting that the plate boundary forces that govern plate motions are also responsible for the first-order pattern of stress [e.g., Zoback, 1992; Coblentz and Richardson, 1995]. As a result, two-dimensional modeling efforts, including global [e.g., Solomon et al., 1975; Richardson et al., 1979] and single plate studies [e.g., Cloetingh and Wortel, 1986; Richardson and Reding, 1991; Coblentz and Richardson, 1996; Wang et al., 1997; Pacanovsky et al., 1999], have made use of the intraplate stress pattern to constrain the tectonic forces. In this study the same methodology is for the first time applied to a ridge overlap or microplate system. The pattern of lithospheric stress inferred from observations at Easter microplate is compiled and modeled using the finite element method. The objective is to determine the forces governing Easter microplate rotation and to assess their relative magnitudes.

\section{Stress Indicators at Easter Microplate}

[9] The stress indicators at Easter microplate are the morphological and structural observations, summarized in Figures 2 and 3, and the earthquake focal mechanism solutions between 1963 and 2000, displayed in Figure 4. We use the earthquake information to constrain the stress directions inferred from the structural observations when several focal mechanisms in the same region show consistent directions of tension and compression axes.

[10] The eastern and western boundaries of the microplate, called the East and West Rifts (Figure 2), display a tectonic pattern typical of other spreading segments and propagating rifts of the East Pacific Rise: normal faulting roughly parallel to the spreading axis, pseudofaults associated with the propagating rifts, and tectonically rotated fabric at the overlapping spreading centers and propagating rifts [e.g., Searle et al., 1989]. Figure 4 shows both strikeslip and normal focal mechanisms along the East and West Rifts, with normal solutions predominating near the rift tips (northern end of East Rift and southern end of West Rift). This suggests there is a component of shear along the rifts, and a tensile component, progressively stronger toward the rift tips, which is perpendicular to the rift strike and characteristic of mid-ocean ridges in general.

[11] The southern boundary of the microplate is not well defined (Figure 2). Its western end consists of two elevated ridges, composed of en echelon scarps separated by short offsets. Francheteau et al. [1988] interpreted a 2-km-wide valley that runs into the southern ridge at $26^{\circ} 45.5^{\prime} \mathrm{S}$, $114^{\circ} 50^{\prime} \mathrm{W}$, as the first expression of a transform fault which they called the Orongo fracture zone. The earthquake focal mechanisms along the southern boundary of the microplate indicate a NW-SE direction of maximum compression (Figure 4). The strike of the Orongo fracture zone is WNW-ESE, so the earthquakes can be related with rightlateral strike-slip motion along WNW-ESE fault planes. To the east, between the Orongo fracture zone and the East Pacific Rise, the tectonic fabric includes ridges and scarps of varying trend, but no evidence of any defined plate boundary [Francheteau et al., 1988; Searle et al., 1989]. It is therefore not possible to decide if the observed earthquakes are related to right-lateral strike slip motion along NW-SE planes or left-lateral strike slip motion along NESW planes.

[12] The eastern end of the northern boundary is a broad (70-100 km) zone of high-relief, nested grabens, enclosing the $5980 \mathrm{~m}$ deep "Pito deep" at $23^{\circ} \mathrm{S}, 111^{\circ} 6^{\prime} \mathrm{W}$ (Figure 2). Between the Pito deep and $113^{\circ} 00^{\prime} \mathrm{W}$, Francheteau et al. [1988] interpreted a narrow band of ENE-WSW trending faults as a transform fault with almost pure strike-slip movement, and named it the Pito fracture zone. To the west, the northern boundary of the microplate consists of a continuous series of broad $(15-35 \mathrm{~km}$ wide), high relief $\left(1-2 \mathrm{~km}\right.$ high) ridges, following roughly $23^{\circ} \mathrm{S}$ latitude [Francheteau et al., 1988; Searle et al., 1989]. The strike and elevation of the northern boundary, especially in its western half, is consistent with an approximately N-S direction of maximum compression. This direction of compression is also consistent with a series of high-relief E-W trending ridges observed in the Nazca plate (Figure 3). These ridges, scattered from around $22^{\circ} \mathrm{S}, 114^{\circ} \mathrm{W}$ (close to the EPR) to near the Pito deep area (Figure 2), vary in length between 20 and $50 \mathrm{~km}$ and some stand more than 1 $\mathrm{km}$ above the surrounding seafloor [Rusby and Searle, 1993].

[13] The estimates of relative plate motions lead to the calculation of the Easter-Nazca rotation pole at about $22.5^{\circ} \mathrm{S}, 112.4^{\circ} \mathrm{W}$ (Figure 4) [Naar and Hey, 1989; Rusby and Searle, 1995]. This pole predicts a N-S component of motion along the northern boundary, decreasing toward the east, combined with an east-west strike-slip component that increases toward the east. The existence of the compressional ridges in the Nazca plate suggests that the northern boundary of the microplate is unable to accommodate all the convergence between the Easter and Nazca plates and that the Nazca plate has been undergoing compressional deformation. The asymmetry and steepness of these ridges led 

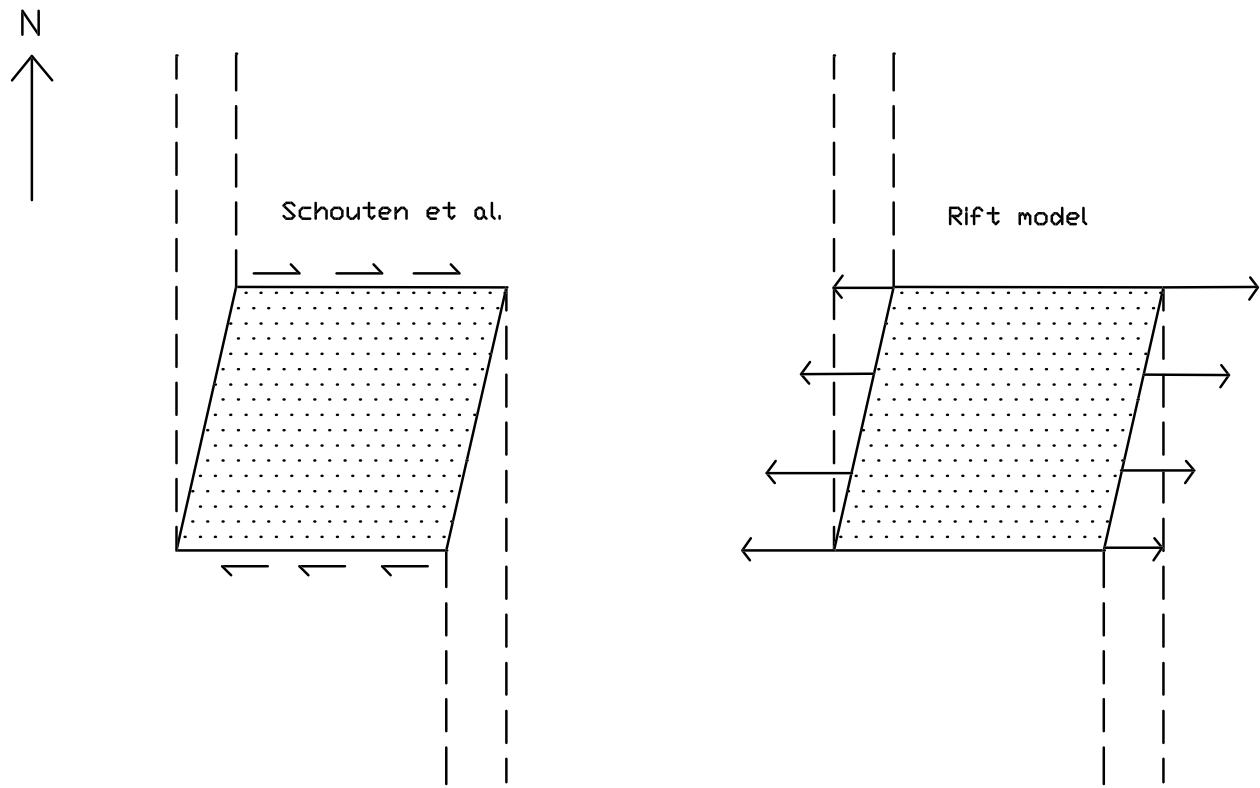

Figure 1. Schouten et al. [1993] model versus the new rift model. The dotted area represents the microplate, bounded at the top and bottom by the northern and southern boundaries respectively, and bounded laterally by the East and West Rifts. Dashed lines represent isochrons and illustrate the accretion gradient along the microplate margins (the spreading rate decreases northward along the East Rift and decreases southward along the West Rift). In the Schouten et al. model, the microplate is driven by shear forces along the northern and southern boundaries, produced by the drag of the main plates. In the new rift model, the microplate is driven by the clockwise torque produced by the gradient in the ridge resistance along the East and West Rifts.

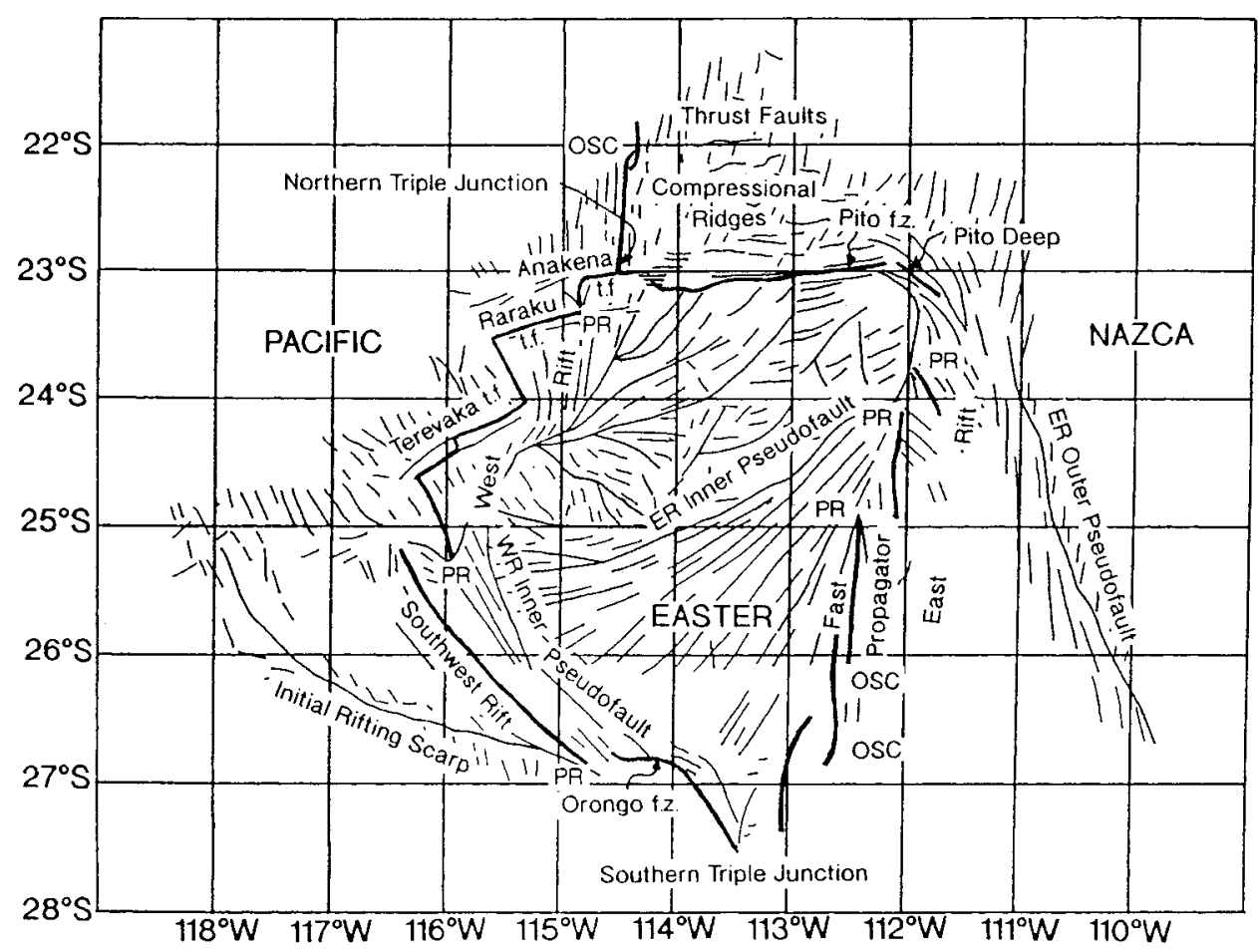

Figure 2. Simplified tectonic interpretation of Easter microplate based on GLORIA sidescan sonar data. Location names are used throughout the text (t.f., active transform fault; f.z., fracture zone; PR, propagating rift; OSC, overlapping spreading center; ER, East Rift; and WR, West Rift) [after Rusby and Searle, 1995]. 

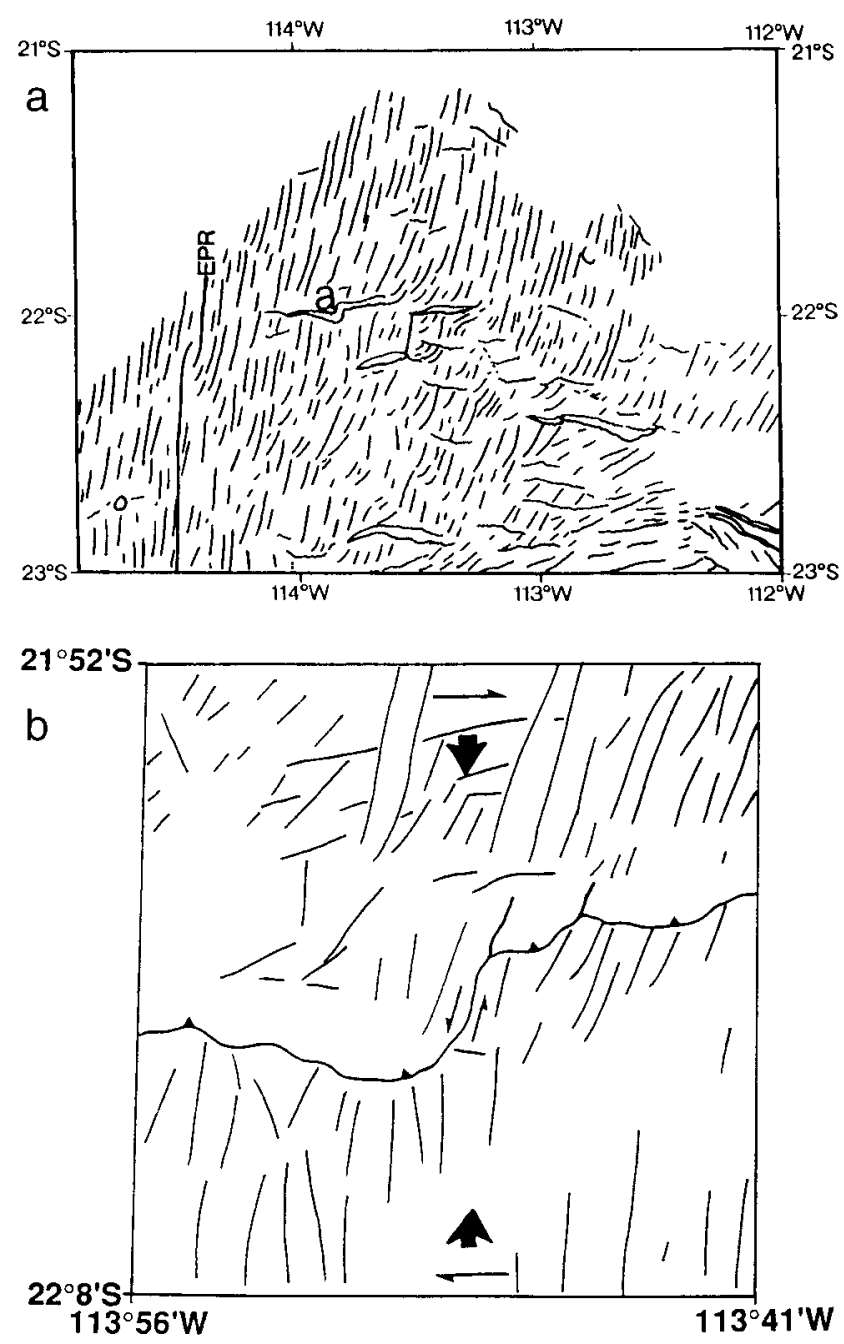

Figure 3. (a) Interpretation of GLORIA image of part of Nazca plate north of Easter microplate. Normal fault scarps formed at the East Pacific Rise are orthogonal to the spreading direction. Large, broad, east-west trending features, crosscutting the normal faults, are asymmetric ridges (confirmed by bathymetric data). (b) Close-up of ridge labeled $\mathrm{a}$ in the top diagram. The pair of asymmetric ridges appears to be linked by a transfer fault. The abrupt termination of the EPR-parallel spreading fabric against steep, south facing slopes, as well as the sharp base of those slopes, indicates the ridges have a faulted origin. Arrows indicate dextral transpressive stress (combination of northsouth compression and east-west dextral shear) [after Rusby and Searle, 1993].

Rusby and Searle [1993] to propose that they were actually thrust faults.

[14] The average N-S direction of compression inferred from the structural observations is confirmed by the focal mechanism evidence showing that the direction of the compression axis in the north of Easter microplate and in the adjacent Nazca plate is consistently NNE-SSW (Figure 4). The large majority of the earthquakes show strike-slip motion combined with a component of thrust. The strikeslip mechanisms are compatible with right-lateral motion along WNW-ESE fault planes. The component of thrust is substantiated by three thrust mechanisms, two observed in Nazca and the other in the NW corner of the microplate.

\section{Strength of the Microplate}

[15] In order to estimate plate boundary forces and to compare modeled stresses with the stress indicators and plate breaking stresses, we need to estimate the strength of the lithosphere in the microplate.

\subsection{Lithospheric Strength}

[16] Flexural models at the East Pacific Rise commonly predict that the elastic lithosphere is $1-2 \mathrm{~km}$ thick at about $10 \mathrm{~km}$ from the ridge axis and that it gradually thickens away with the square root of age [e.g., Kuo et al., 1986; Wang and Cochran, 1993; Eberle and Forsyth, 1998; Shah and Buck, 2001]. It is therefore expected that within the Easter microplate the elastic lithosphere is thicker than 1$2 \mathrm{~km}$. Since the ductile lower lithosphere can withstand very small deviatoric stress compared to the upper rigid lithosphere, we assume that the elastic lithosphere within the microplate acts as a stress guide and that away from the plate boundaries we can neglect the contribution of the ductile lower lithosphere to the overall strength. Within the elastic or brittle region of the lithosphere the strength is determined from the Byerlee law [Byerlee, 1978], and the maximum tectonic stress (i.e., the maximum horizontal deviatoric stress) that can be withstood is twice the Byerlee-based rock strength law. In the thrust and normal fault regimes the maximum tectonic stress for hydrostatic pore fluid pressure can be written as [Turcotte and Schubert, 1982]

$$
S=\frac{\mp 2 f_{s}\left(\rho g z-\rho_{w} g z\right)}{\left(1+f_{s}^{2}\right)^{1 / 2} \pm f_{s}}
$$

where the upper sign gives the maximum tectonic stress in extension and the lower sign gives the maximum tectonic stress in compression. The coefficient of friction, $f_{s}$, varies between 0.6 and 0.85 for most rocks [Byerlee, 1978; Brace and Kohlstedt, 1980]. The meaning and value of the other symbols are listed in Table 1. Note that the formula uses the depth $\mathrm{z}$ below the seabed rather than the sea surface [Neves, 2000].

[17] In the transcurrent fault regime, the vertical stress, which is usually assumed to be the lithostatic pressure, is the intermediate stress. In this case the maximum tectonic stress is harder to determine because both the maximum and minimum principal stresses are unknown. Nevertheless, the maximum tectonic stress can be derived by writing the intermediate stress as

$$
\sigma_{z z}=\sigma_{3}+\delta\left(\sigma_{1}-\sigma_{3}\right),
$$

where $\sigma_{z z}$ is the vertical stress, $\sigma_{3}$ is the minimum principal stress, $\delta$ is a dimensionless factor $0<\delta<1$, and $\sigma_{1}$ is the maximum principal stress. With this definition the maximum tectonic stress in the transcurrent fault regime is

$$
S=\frac{2 f_{s}\left(\rho g z-\rho_{w} g z\right)}{\left(1+f_{s}^{2}\right)^{1 / 2}-f_{s}(1-2 \delta)} .
$$




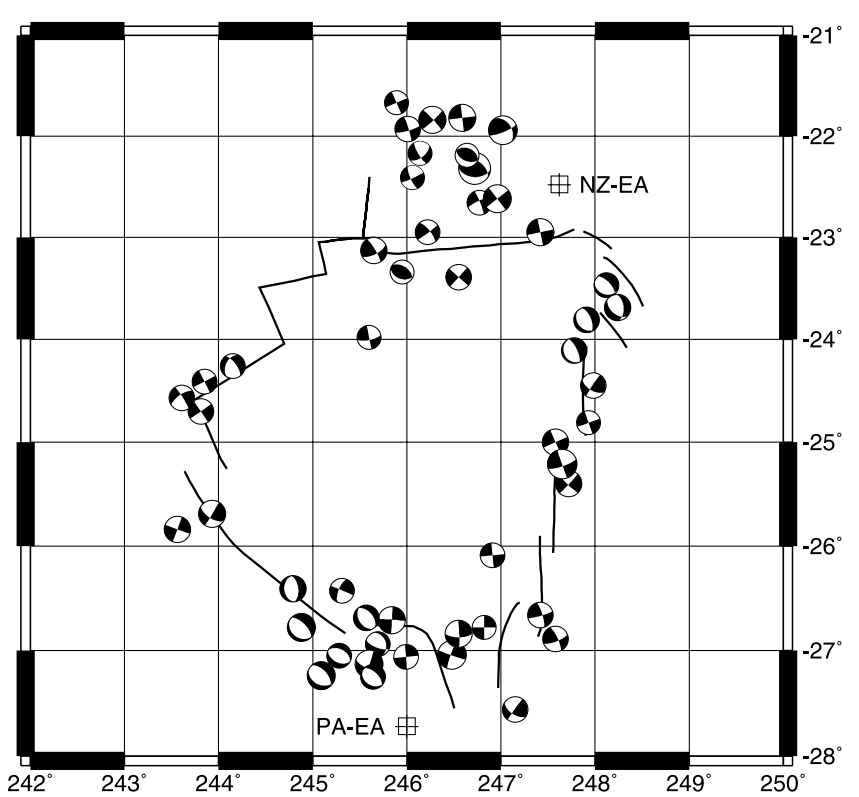

Figure 4. Earthquake focal mechanisms compiled from Engeln and Stein [1984] for earthquakes until 1965, and from the centroid moment tensor solutions [Dziewonski and Woodhouse, 1983] for earthquakes after 1965. The crossed squares show the location of the NZ-EA and PA-EA threeplate closure poles calculated by Rusby and Searle [1995]. $P$ axis in the white quadrant. Size indicates the earthquake's relative magnitudes.

[18] For $\delta=0.5$ equations ( 1 ) and (3) can be written in the condensed form

$$
S=\alpha\left(\rho g z-\rho_{w} g z\right),
$$

where $\alpha$ depends on the fault type. For a fault with coefficient of friction $f_{s}=0.75$ we get $\alpha=3.0$ for thrust faults, $\alpha=1.2$ for strike-slip faults and $\alpha=0.75$ for normal faults.

[19] The maximum tectonic stress $S$ integrated over the thickness of a layer yields the maximum tectonic force, $F$, that a unit length perpendicular to strike can withstand, and will be referred to as the layer strength (in units of N/m). $F$ therefore varies as the square of the brittle thickness. Estimates of the layer strength of the lithosphere in the normal, strike-slip, and thrust faulting regimes for several estimates of the brittle layer thickness are listed in Table 2. Lower and upper limits correspond to coefficients of friction of 0.6 and 0.85 respectively. We consider variations in the plate thickness later.

\subsection{Strength at the Microplate Boundaries}

[20] The strength at the microplate boundaries is important in assessing the maximum driving and resistive boundary stresses that can be withstood along its vertical edges.

Table 1. Strength Envelope Parameters

\begin{tabular}{lc}
\hline \multicolumn{1}{c}{ Symbol } & Value \\
\hline Density of seawater $\rho_{w}$ & $1030 \mathrm{~kg} / \mathrm{m}^{3}$ \\
Density of crust $(\mathrm{z}<6 \mathrm{~km}) \rho_{c}$ & $2950 \mathrm{~kg} / \mathrm{m}^{3}$ \\
Density of mantle $(\mathrm{z}>6 \mathrm{~km}) \rho_{m}$ & $3300 \mathrm{~kg} / \mathrm{m}^{3}$ \\
Acceleration due to gravity $g$ & $9.8 \mathrm{~m} / \mathrm{s}^{2}$ \\
Fault's coefficient of friction & $0.6 \leq f_{s} \leq 0.85$ \\
\hline
\end{tabular}

Table 2. Lithospheric Strength With Maximum Tectonic Force $F$

\begin{tabular}{clcl}
\hline $\begin{array}{c}\text { Brittle Thickness, } \\
\mathrm{km}\end{array}$ & $\begin{array}{l}F_{\text {normal }}, \times \\
10^{9} \mathrm{~N} / \mathrm{m}\end{array}$ & $\begin{array}{l}F_{\text {strike-slip }}, \times \\
10^{9} \mathrm{~N} / \mathrm{m}\end{array}$ & $\begin{array}{c}F_{\text {thrust }}, \times \\
10^{9} \mathrm{~N} / \mathrm{m}\end{array}$ \\
\hline 1 & $6-7$ & $10-12$ & $20-35$ \\
2 & $26-30$ & $39-49$ & $80-138$ \\
4 & $102-118$ & $155-195$ & $319-553$ \\
8 & $442-511$ & $669-842$ & $1378-2390$ \\
\hline
\end{tabular}

\subsubsection{Northern Boundary}

[21] The strength in the western part of the northern boundary of the microplate is particularly important because of the evidence of brittle failure in compression in the adjacent region to the north. The nearest thrust fault to the East Pacific Rise in the Nazca plate has its western end at 24 $\mathrm{km}$ from the ridge axis, corresponding to $0.3 \mathrm{Ma}$ lithosphere [Rusby and Searle, 1993]. Analyzing the variation of gravity and bathymetry over the East Pacific Rise, Wang and Cochran [1993] suggested that for fast spreading ridges the effective elastic thickness of the plate, $T_{e}$, in $\mathrm{km}$, is given by

$$
T_{e}=0.1+R x^{\frac{1}{2}},
$$

where $x$ is distance from the spreading axis $(\mathrm{km})$ and $R$ is a parameter between 0.2 and $0.3 \mathrm{~km}^{1 / 2}$. An elastic thickness of $0.9-1.4 \mathrm{~km}$ is estimated for $0.3 \mathrm{Ma}$ lithosphere using this expression. Consequently, we assume that thrust faulting occurs when the Nazca brittle plate is at least $1 \mathrm{~km}$ thick, which requires a compressive tectonic force larger than 20$35 \mathrm{GN} / \mathrm{m}$ (Table 2) near the western end of the northern boundary.

\subsubsection{East and West Rifts}

[22] The strength at the East and West Rifts accounts for the ridge resistance, and is the key parameter of our riftdriven hypothesis for Easter microplate rotation. Theoretical and numerical models at mid-ocean ridges suggest that the maximum tectonic stress resisting plate separation is of the order of tens of megapascals, and varies inversely with spreading rate [Lachenbruch, 1973; Tapponnier and Francheteau, 1978; Sleep and Rosendahl, 1979; Phipps Morgan et al., 1987; Chen and Morgan, 1990; Lin and Parmentier, 1990; Neumann and Forsyth, 1993; Poliakov and Buck, 1998]. The brittle thickness at the spreading axis is also inversely correlated with spreading rate. Both seismic evidence and thermomechanical and gravity modeling show that the brittle plate thickness at slow spreading ridges is on average 2 to $6 \mathrm{~km}$ thicker than at fast spreading ridges (e.g., Detrick et al. [1987], Huang and Solomon [1988], Lin et al. [1990], Purdy et al. [1992], and Owens [1996], as reported by Searle et al. [1998]). Distributions of earthquake epicenters on the Mid-Atlantic Ridge suggest thicknesses up to about $8 \mathrm{~km}$ [Kong et al., 1992; Wolfe et al., 1995; Toomey et al., 1988; Barclay et al., 2001], and values up to $9 \mathrm{~km}$ at the ultraslow spreading (14 mm/yr full rate) South West Indian Ridge (T. Yamada et al., Microearthquake characteristics at the Jourdanne segment, http://triton.ori.u-tokyo.ac.jp/ intridge, 2002). Further evidence that slow spreading ridges have greater brittle strengths than fast spreading ones is provided by their relatively higher levels of seismicity, larger fault throws, and general rougher topography.

[23] The variation of the spreading rate along the East and West Rifts has been derived by Rusby [1992] from magnetic anomaly data and kinematic modeling. The full spreading 
rate along the East Rift decreases from $\sim 139 \mathrm{~mm} / \mathrm{yr}$ at $27^{\circ} \mathrm{S}$ to $\sim 18 \mathrm{~mm} / \mathrm{yr}$ at $23^{\circ} \mathrm{S}$. Similarly, the full spreading rate along the West Rift changes from $\sim 136 \mathrm{~mm} / \mathrm{yr}$ at $23^{\circ} \mathrm{S}$ to $\sim 20 \mathrm{~mm} / \mathrm{yr}$ at $27^{\circ} \mathrm{S}$. The overall morphology of the rifts is affected by this spreading rate change: far from the rift tips, where spreading is fast, the "rifts" have the appearance of a normal fast spreading ridge with small fault scarps and an axial high, while at the slow spreading rift tips (especially the East Rift), large-scale axial grabens with large normal faults are formed, suggesting a stronger lithosphere here [e.g., Martinez et al., 1991]. As a consequence, the ridge resistance must increase toward the tip of each rift, that is, northward along the East Rift and southward along the West Rift.

[24] To quantify the ridge resistance at the East and West Rifts we would like to use the brittle strength estimates determined above (Table 2). However, these estimates can only be used with confidence near the rift tips, where we expect a major contribution of the (thick) brittle layer to the overall strength. Near the rift ends, where normal East Pacific Rise spreading rates exist and the axial elastic lithosphere may not be thicker than $0.1-0.2 \mathrm{~km}$ [e.g., Kuo et al., 1986; Wang and Cochran, 1993], the contribution of the brittle layer to the strength must be very small. This does not imply very small strength near the rift ends. Thus recent models of the axial high at the East Pacific Rise indicate that the ductile lower crust at the ridge axis may significantly contribute to the overall strength (e.g., Eberle and Forsyth [1998] suggest the viscous lower crust may contribute with $10 \mathrm{GN} / \mathrm{m}$, more than the estimated strength of a brittle layer $1 \mathrm{~km}$ thick). Another argument in favor of significant strength near rift ends may be that the rate of thickening of the lithosphere away from the ridge axis is so fast that the strength of the plate boundary is likely to depend on a mean thickness averaged over the innermost few kilometers (e.g., Shah and Buck [2001] suggest the elastic layer could become $\sim 2 \mathrm{~km}$ thick at less than $5 \mathrm{~km}$ from the East Pacific Rise axis).

[25] We thus do not use direct estimates of the varying plate thickness or strength as inputs to our models, but rather determine the maximum tectonic force required by the models, infer the equivalent plate thickness, and discuss how realistic this is. Moreover, we only use the brittle strength to compute the equivalent plate thickness at the rift tips.

\section{Modeling Assumptions and Procedure}

[26] The stress field at Easter microplate is calculated using two-dimensional horizontal finite element models. The boundaries adopted and the grid used in the calculations are shown in Figure 5. The right and left boundaries of the grid represent the East and West Rifts respectively. The northern boundary is represented by the straight line at the top. The southern boundary, although not well defined in reality, is represented at the bottom by the simplest configuration, which is also a straight line.

[27] The models are elastic. This hypothesis applies inside the microplate, where the observations indicate small total deformation. Young's modulus is taken as $E=0.7 \times$ $10^{11} \mathrm{~Pa}$ and the Poisson's ratio is $\nu=0.25$. Only the nonlithostatic stress is modeled. Possible variations in lithospheric thickness are negligible compared with Easter microplate horizontal dimensions, and as a result the tec-

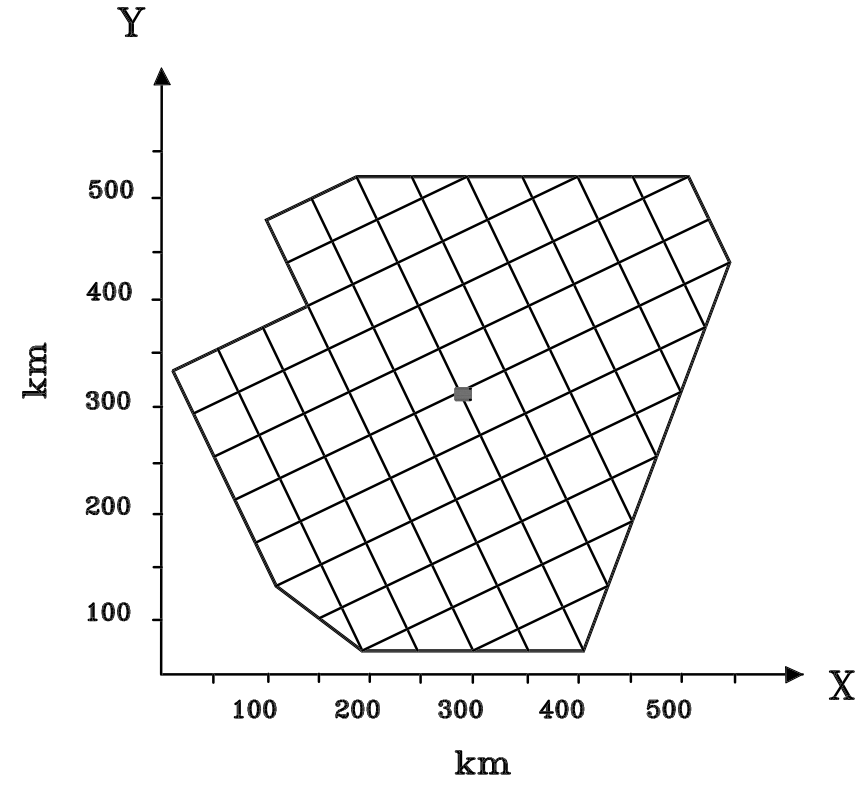

Figure 5. Finite element grid used to represent Easter microplate. The square indicates the location of the centre of rotation for the basal drag models.

tonic force (the product of the tectonic stress by the thickness) in the microplate is approximately conserved, i.e., is approximately independent of the model thickness. All the quantities in the models are averaged over the model thickness, which is assumed to be constant. The actual nonlithostatic stress in a microplate of varying thickness can then be calculated by inverse linear scaling.

[28] The plane stress assumption is used. The applied and resistive forces are all horizontal, and the top surface of the plate is free, implying that there are no vertical nonlithostatic stresses. As the vertical stress (less lithostatic component) is zero, thrust, normal, and transcurrent regimes can be readily identified using Anderson's theory of faulting. If both horizontal principal stresses are compressive there is a thrust fault regime. If both horizontal principal stresses are tensile there is a normal fault regime. If one of the horizontal principal stresses is compressive and the other is tensile there is a strike-slip fault regime.

[29] The fundamental hypothesis of the modeling procedure is that the microplate is in dynamical equilibrium. Tectonic plates move at very slow rates, so in general the acceleration of the plates can be neglected. Also, the rotation rate of Easter microplate has been constant over the last 3 Myr [Schouten et al., 1993; Searle et al., 1993], so there is no angular acceleration. The relatively small dimensions of Easter microplate justify the flat plate approximation. The equilibrium condition then implies that the total torque about a vertical axis, exerted by all the forces acting on the plate, must be zero. Thus the microplate must be subjected to a combination of driving and resisting torques, which are in equilibrium. The resisting torques are assumed to result from (1) resisting forces acting along the northern and southern boundaries of the microplate and (2) the mantle basal drag, distributed over the base of the microplate. The driving torque is assumed to be due to the drag of the main plates, either in the form of shear forces 
applied along the northern and southern boundaries of the microplate (Schouten et al. hypothesis), or in the form of normal forces applied along the East and West Rifts (riftdriven hypothesis).

\section{Resisting Forces Along the Northern and Southern Boundaries}

[30] The stress indicators at Easter microplate suggest that both shear and normal forces exist along these boundaries. We consider two possibilities corresponding to two types of boundary conditions:

[31] 1. There are both shear and normal forces along the whole length of the northern and southern boundaries.

[32] 2. There are only normal forces in the half-length of the northern and southern boundaries away from rift tips.

[33] Shear and normal forces acting simultaneously create transcurrent faulting conditions, which are consistent with the earthquake focal mechanism solutions and the existence of the Pito and Orongo fracture zones. Normal forces along the northern boundary are suggested by the compressional ridges in the Nazca plate, as well as the elevation of the northern boundary itself. For simplicity these normal forces are mirrored along the southern boundary.

[34] However, the crust is much weaker in tension than in compression. Because the crust near the rift tips is subjected to tension, and the rifts tips curve toward the northern and southern boundaries, the halves of the boundaries adjacent to the rift tips may have effectively free boundaries. The other halves, with transcurrent faulting conditions, may subsequently become weak relative to shear displacement, so that the boundary becomes constrained only in the normal direction.

[35] The resistances along the northern and southern boundaries are included in the analysis by fixing the appropriate boundary nodes to zero displacement. If the boundary is fixed in both directions then both shear and normal forces can exist along that boundary. If the boundary is only fixed in the direction parallel or perpendicular to it, then only shear or normal forces, respectively, can exist along that boundary.

\section{Mantle Basal Drag}

[36] The mantle basal drag force quantifies the interaction between the lithosphere and the asthenosphere. In plate tectonic numerical models the basal drag is commonly computed [e.g., Richardson et al., 1979] from

$$
\vec{F}_{D}=D \vec{V}
$$

where $\vec{F}_{D}$ is the mantle drag force per unit area, $D$ is a constant of proportionality, and $\vec{V}$ is the absolute velocity of the plate in a fixed hot spot reference frame. Since Easter microplate is rotating relative to the Nazca and Pacific plates, its absolute motion can be decomposed into a rotation about an axis fixed relative to the microplate and a translation of that axis. The component of translation has no relevance when the forces governing Easter microplate rotation are being analyzed. The component of rotation is given by the vector product of the angular velocity $\vec{\omega}$ (about a vertical axis fixed to the microplate) and the distance to the rotation axis, $\vec{r}$. The mantle basal drag due to the rotation component is therefore

$$
\vec{F}_{D}=D(\vec{\omega} \times \vec{r})
$$

If the rotation of the microplate is driven by the asthenospheric flow, then there must be a vortex in the asthenosphere having increasing angular velocity with depth. This hypothesis is disregarded on the grounds of implausibility, and consequently it is assumed that the mantle basal drag resists the microplate rotation. According to equation (6) the magnitude of the basal drag increases with the distance from the rotation axis. The basal drag, being a resisting force, acts in an anticlockwise direction since the microplate rotates in a clockwise direction.

[37] The angular velocity of Easter microplate during the last 3 Myr, estimated from the magnetic anomalies and predicted by the roller-bearing model, has been about $18 \%$ Myr [Schouten et al., 1993; Searle et al., 1993; Cogné et al., 1995]. Using this rotation rate we calculate a basal drag that is tangent to circles about the centre of the microplate shown in Figure 5.

[38] To determine the constant of proportionality $D$ of equations (5) and (6), the asthenosphere is considered to be a low-viscosity constant thickness channel, bounded at its top by a moving lithosphere and at its bottom by a motionless mesosphere. As a first approximation we assume that circular flow produces the same shear stress as 2-D channel Couette flow [e.g., Liggett, 1994]. The velocity profile of a Newtonian fluid moving with velocity $u$ in the horizontal $x$ direction, in a channel of constant thickness $h$, under no applied horizontal pressure gradient, and with boundary conditions $u=V$ at the top of the channel $(y=0)$, and $u=0$ at the base $(y=h)$, is [Turcotte and Schubert, 1982]

$$
u=V(1-y) / h \text {. }
$$

As a result of the gradient in the velocity profile, a shear stress is exerted on horizontal planes in the asthenosphere and at the base of the lithosphere. The shear stress at the base of the lithosphere is

$$
\tau=\eta\left|\frac{d u}{d y}\right|=\eta \frac{V}{h}
$$

where $\eta$ is the viscosity of the asthenosphere. Making $\tau$ of equation (8) equal to $F_{D}$ of equation (5) gives $D=\eta / h$. Then, the expression of the basal drag becomes

$$
\vec{F}_{D}=\frac{\eta}{h}(\vec{\omega} \times \vec{r}) .
$$

Easter microplate is a large mid-ocean ridge offset, so the asthenospheric viscosity beneath the microplate is likely to be close to that beneath mid-ocean ridges. The few observational constraints on the viscosity of the asthenosphere near mid-ocean ridges indicate values between $10^{18}$ $\mathrm{Pa} \mathrm{s}$ and $10^{19} \mathrm{~Pa}$ s. For instance, models of small-scale mantle convection consistent with the gravity lineations observed in satellite data near the East Pacific Rise suggest 
a minimum of $10^{18} \mathrm{~Pa}$ s [Buck and Parmentier, 1986]. Postglacial rebound data in Iceland require upper mantle viscosity values lower than $10^{19} \mathrm{~Pa}$ s [Sigmundsson, 1991]. We assume that the asthenospheric viscosity beneath Easter microplate may have a value in the range between $1 \times 10^{18}$ $\mathrm{Pa} \mathrm{s}$ and $1 \times 10^{19} \mathrm{~Pa} \mathrm{~s}$, and that the asthenosphere channel is $200 \mathrm{~km}$ thick.

[39] In the finite element model the magnitude of the basal drag is maximum at the boundaries of the grid. Using $r=240 \mathrm{~km}, \omega=18^{\circ} / \mathrm{Myr}$ and $h=200 \mathrm{~km}$ in equation (9) gives

$$
\begin{array}{ll}
F_{D} \approx 0.012 \mathrm{MPa} & \eta=1 \times 10^{18} \mathrm{~Pa} \mathrm{~s} \\
F_{D} \approx 0.12 \mathrm{MPa} & \eta=1 \times 10^{19} \mathrm{~Pa} \mathrm{~s} .
\end{array}
$$

These values are in conformity with generally accepted estimates of the basal drag magnitude in the range $10^{-1}$ $10^{-2} \mathrm{MPa}$ [e.g., Richardson et al., 1979; Richardson and Reding, 1991; Wortel et al., 1991].

[40] Since the models are 2-D horizontal, the vertical variation of the shear stress within the plate is neglected, and the basal drag has to be averaged over the elastic plate thickness. The elastic thickness in the microplate is not constant, but as already explained the tectonic force is approximately independent of the model thickness. So we assume the model has unit thickness, knowing that at any point the actual stress is equal to the modeled stress multiplied by the inverse of the actual elastic thickness. The value of the basal drag that is input to the models is thus $F_{D}$ divided by $1 \mathrm{~km}$. This input value has the dimensions of a force per unit volume, i.e., a stress per unit length. The modeling program deals with the basal drag as a horizontal body force.

\section{Schouten et al. Model}

[41] In the ideal kinematic model proposed by Schouten et al. [1993] the drag forces driving the microplate rotation are tangent to the microplate boundaries and act at two single points, which are simultaneously the tips of the propagating rifts and the instantaneous poles of rotation of Easter relative to Nazca and Pacific plates. Here we test the idea of a microplate being driven by drag forces distributed along its boundaries. In practice this is more reasonable than having all the drag concentrated at only two points. Drag forces tangent to the microplate boundaries are in fact shear forces. Because mid-ocean ridges are associated with extension it is not realistic to consider just shear forces along the East and West Rifts. The driving forces consistent with the Schouten et al. hypothesis are therefore shear forces distributed along the northern and southern boundaries of the microplate.

[42] To test the Schouten et al. model, we assume: (1) shear driving forces along the northern and southern boundaries increasing linearly toward the boundary center (the ability to sustain shear forces is expected to increase with the plate thickness and age, i.e., away from the rifts); (2) free boundary conditions along the East and West Rifts (if the rifts are too weak to transmit the main plate's drag then they are too weak to resist the microplate rotation); (3) a mantle basal drag contributing to $20 \%$ of the total resisting torque (we show in the next section that this gives the best fit); and (4) $80 \%$ of the resistance to the microplate rotation coming from normal forces along the whole length of the northern and southern boundaries (model SCHW, Figure 6), or just along approximately the half-length away from rift tips (model SCHH, Figure 6).

[43] Recalling that there is not enough information to constrain the stress directions along the southern boundary of the microplate, we seek a model predicting strong average N-S compression in the western part of the northern boundary (the best constrained stress direction).

[44] In interpreting Figure 6 we must beware the edge effects due to the geometry of the grid and to abrupt changes in the boundary conditions. The abrupt changes in the boundary conditions (e.g., from locked in the normal direction to unlocked) are artificial since in nature they are expected to be gradual. Nevertheless, it can be observed that model SCHH (Figure 6) gives the best fit to the strong compression in the western part of the northern boundary. Other boundary conditions were tested, in particular other distributions of shear driving and normal resisting forces (model SCHW in Figure 6 is an example), but these tests only proved that strong N-S compression in the NW corner of the microplate requires the driving shear forces and the normal resistances to be concentrated in the half length of the boundary away from the East Rift tip.

\section{Rift-Driven Hypothesis}

[45] Another way the drag of the main plates can be applied to the microplate is along the East and West Rifts, provided these have enough strength. At the latitude of Easter microplate the Nazca plate is moving with an azimuth of approximately $103^{\circ}$ relative to the Pacific plate [DeMets et al., 1990]. For simplicity we will assume the drag of the main plates is approximately E-W. This drag then combines a normal tension component along the rifts, characteristic of mid-ocean ridges, and a shear component that points south along the East Rift and north along the West Rift. Because of the increasing ridge resistance both the normal and the shear components of the drag are expected to increase toward the rift tips.

[46] The E-W pull applied to the East and West Rifts increases from zero at the rift tail to $15 \mathrm{GN} / \mathrm{m}$ at the rift tip. Such a force distribution produces a driving torque which is in equilibrium with the resisting torque produced by the mantle basal drag computed for an asthenosphere viscosity of $5 \times 10^{18} \mathrm{~Pa} \mathrm{~s}$ (if no other resistances are included).

[47] In models RIFT1 to RIFT5 (Figure 7) in addition to the E-W pull and mantle basal drag we use normal resistances restricted to approximately the half-length of the northern and southern boundaries away from rift tips. To assess the relative contribution of the mantle basal drag to the total resisting torque, the asthenosphere viscosity values, used in the mantle basal drag calculation, increase in steps of $1 \times 10^{18} \mathrm{~Pa} \mathrm{~s}$, from $1 \times 10^{18} \mathrm{~Pa}$ in model RIFT1 to $5 \times$ $10^{18} \mathrm{~Pa} \mathrm{~s}$ in model RIFT5.

[48] The best fit to a strong average N-S direction of compression in the western part of the northern boundary is obtained in model RIFT1. This implies that the best fit to the stress indicators occurs when $80 \%$ of the resistance to 

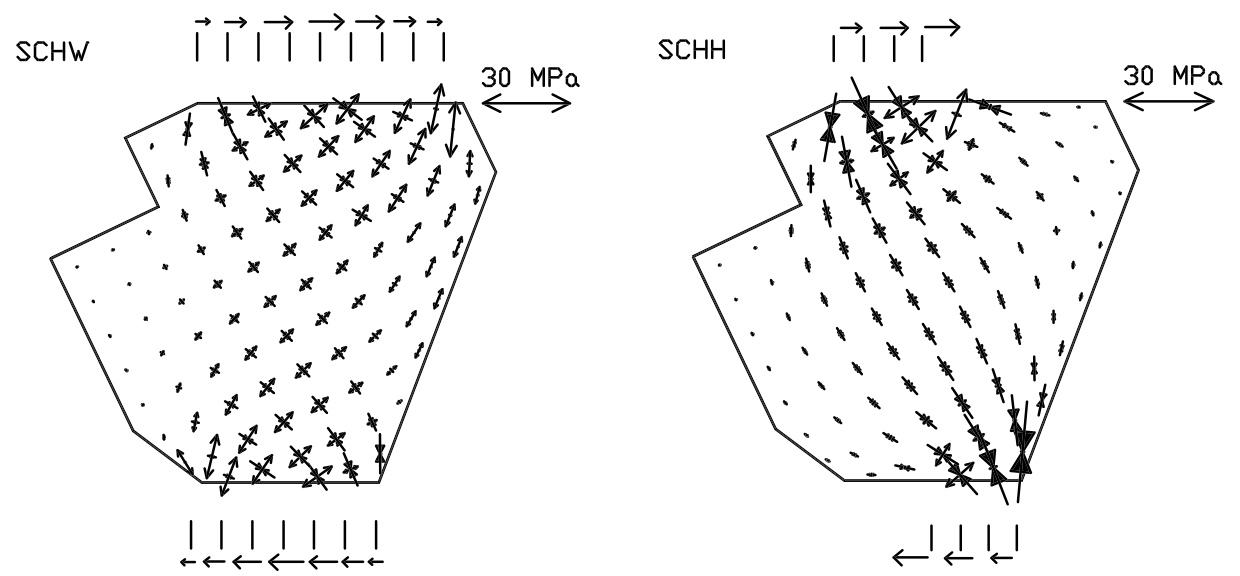

Figure 6. The Schouten et al. model. The boundary conditions are displayed along the northern and southern boundaries: shear driving forces are indicated by arrows, and fixing in the normal direction is indicated by the short vertical lines. The applied shear force per unit of thickness increases to a maximum of 15 and $30 \mathrm{MPa}$ in models $\mathrm{SCHW}$ and $\mathrm{SCHH}$, respectively (in order to produce the same driving torque). The mantle basal drag has been computed for an asthenosphere viscosity of $1 \times 10^{18} \mathrm{~Pa} \mathrm{~s}$.

the driving forces comes from the northern and southern boundaries and only $20 \%$ comes from the mantle basal drag.

\section{Comparison With Strength Estimates}

[49] Both the Schouten et al. (SCHH) and the rift-driven (RIFT1) models can explain the observed N-S direction of compression in the western part of the northern boundary. For each of these driving mechanisms we now investigate the brittle thickness variations required to produce compressional failure in the Nazca plate and to overcome the basal drag. The strength estimates given earlier indicate that compressional failure in the Nazca plate requires a minimum compressive force of $20-35 \mathrm{GN} / \mathrm{m}$ at the western end
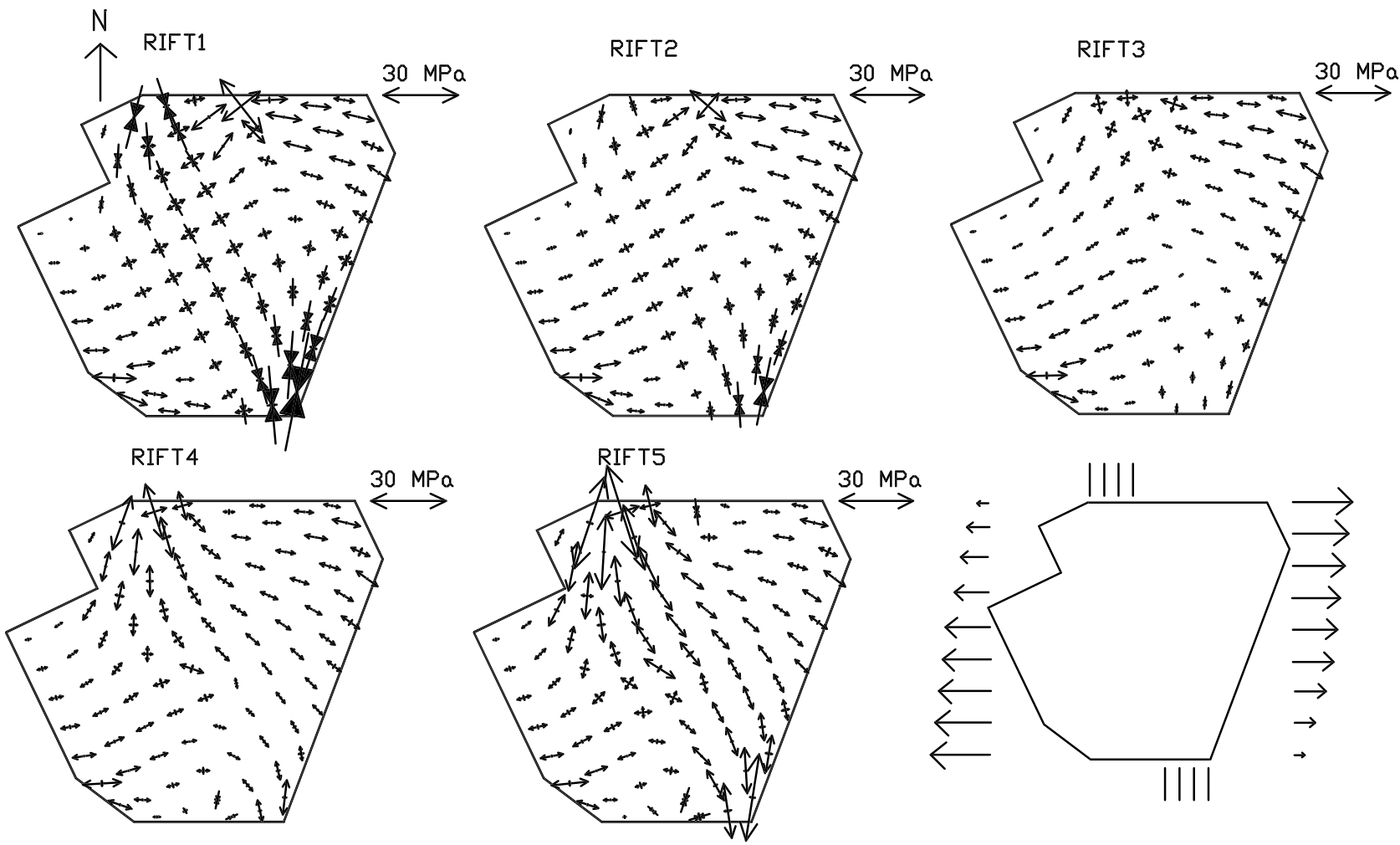

Figure 7. The rift-driven model. The boundary conditions are displayed at the bottom right: driving forces applied along the East and West Rifts are indicated by arrows, and fixing in the normal direction only is indicated by the short vertical lines. The asthenosphere viscosity varies from $1 \times 10^{18} \mathrm{~Pa} \mathrm{~s}$ in model RIFT1 to $5 \times 10^{18} \mathrm{~Pa}$ s in model RIFT5. 
of the northern boundary. Let us consider the mean value of $28 \mathrm{GN} / \mathrm{m}$, which corresponds to $f_{s}=0.75$ and to an average stress of $28 \mathrm{MPa}$ over a 1-km-thick elastic plate (the model thickness).

[50] In model SCHH (Figure 6) the shear driving force applied along the northern and southern half boundaries increases linearly from zero at the rift tails to $30 \mathrm{GN} / \mathrm{m}$ at the boundary centre, producing the required $28 \mathrm{MPa}$ of compression in the western end of the northern boundary. To sustain a tectonic force of $30 \mathrm{GN} / \mathrm{m}$ in the strike-slip regime, the brittle lithosphere is required to be at least 1.6 km thick (see Table 2). Wang and Cochran's [1993] relation gives a minimum plate thickness of $2.9 \mathrm{~km}$ for this part of the microplate, which is at least $200 \mathrm{~km}$ from its spreading axis, and so is more than adequate to transmit the driving force. All other stresses are less than the likely plate strength. We conclude that the Schouten et al. mechanism can drive the microplate from the strength point of view.

[51] In model RIFT1 (Figure 7) the compressive stress in the western end of the northern boundary is also approximately $28 \mathrm{MPa}$, and the driving force applied along the East and West Rifts varies between 0 and $15 \mathrm{GN} / \mathrm{m}$. To accommodate this tensile tectonic force without exceeding the tensile strength, the brittle lithosphere is required to thicken linearly by up to $1.5 \mathrm{~km}$ from rift tails to rift tips. If the base of the seismogenic layer at slow spreading ridges is used as a proxy for the brittle plate thickness at rifts tips (and we note that the morphology at the rift tips is similar to that at the Mid-Atlantic Ridge), then $8 \mathrm{~km}$ is an upper limit for the brittle thickness at the rift tips. In the limit, the brittle plate thickness would be expected to thicken from the less than $1 \mathrm{~km}$ typical of the East Pacific Rise at the rift tails, to $8 \mathrm{~km}$ at the rift tips. The strength of such a brittle layer could easily accommodate tensile stresses along the rifts which would provide more than the torque needed to drive the plate against all the inferred resistances.

[52] The analysis of strength thus indicates that both the rift-driven and the Schouten et al. hypothesis are possible driving mechanisms for the microplate rotation, and therefore the microplate is probably driven by a combination of them. However, because they give rise to very similar stress patterns (models SCHH and RIFT1), it is impossible to determine the partition of the driving torque between these two hypothesis.

\section{Discussion}

\subsection{Asthenosphere Viscosity}

[53] One of the basic premises of our modeling is that the mantle basal drag opposes the microplate rotation. Whether the mantle basal drag is a resisting or a driving force may be controversial at the scale of the large tectonic plates, but a stable vortex in the lower mantle with $500 \mathrm{~km}$ diameter, as required to drive the microplate, seems very implausible. Furthermore, to drive the microplate the mantle basal drag should have a significant magnitude, which is hard to reconcile with the low values of the mantle viscosity expected near mid-ocean ridges. In fact, the asthenosphere viscosity that best fits the stress indicators, $1 \times 10^{18} \mathrm{~Pa} \mathrm{~s}$, falls near the lower limit of the acceptable range of values (perhaps because of the proximity of the Easter hot spot), confirming that the mantle basal drag plays only a small role in the dynamic balance of the microplate (yielding a maximum of $20 \%$ of the total resisting torque).

\subsection{Implications for Microplate Initiation}

[54] The initiation of a microplate requires the overlap of propagating rifts, followed by the development of motion independent from that of the major plates. We also note that ridge-ridge microplates appear to be confined to fast spreading ridges. Commonly such microplates undergo rapid rotations about nearby vertical axes [e.g., Courtillot, 1980; Luyendyk et al., 1980; Engeln and Stein, 1984; Hey et al., 1985; Yelles-Chaouche et al., 1987; Lonsdale, 1988; Searle et al., 1989; Naar and Hey, 1989; Larson et al., 1992; Schouten et al., 1993; Rusby and Searle, 1995]. According to our rift-driven mechanism, larger tensile stresses at rift tips than at rift tails are a necessary condition for microplate rotation. Before rotation can be initiated, the rift tips thus need to produce, or terminate in, a brittle plate thickness substantially greater than normal. Otherwise, a simple transform fault connecting the two offset rift segments would develop rather than a rotating microplate.

[55] Why is it that the known rotating microplates develop at fast spreading ridges, but apparently not at slow spreading ridges such as the Mid-Atlantic ridge? One reason may be that the plate thickness at slow spreading ridges is typically at least $4 \mathrm{~km}$ [e.g., Toomey et al., 1988; Kong et al., 1992] contrasting with the less than $1 \mathrm{~km}$ at the fast spreading East Pacific Rise. As plate strength is inferred to be proportional to the square of thickness, the torque produced by the outward pull of the main plates would need to be at least 16 times greater than that needed at a fast spreading ridge.

[56] Furthermore, whereas at fast spreading environments the spreading rate can decrease from over 100 $\mathrm{mm} / \mathrm{yr}$ at rift tails to zero at the tip of the propagating rifts, at slow spreading ridges it cannot decrease by more than $50 \mathrm{~mm} / \mathrm{yr}$ from tails to tips. Therefore the spreading rate variation along propagating rifts can more easily provide the brittle lithospheric thickening required to drive microplate rotation in fast spreading environments than in slow spreading ones.

[57] Spreading rate is not the only factor controlling lithospheric thickness along propagating rifts. Noting that pseudofaults and slow spreading fracture zones have similar geophysical signatures, Kruse et al. [2000] argue that the existence of thinner crust at propagating rift tips is due to the same processes as the existence of thinner crust at slow spreading fracture zones, namely lack of magma supply, amagmatic extension and possibly low-angle faulting. However, the absence of microplates at slow spreading ridges like the Mid-Atlantic Ridge suggests that these processes also do not cause enough brittle lithospheric thickening along rifts to drive rotation against the resisting forces.

[58] Finally, in the Schouten et al. model the driving forces and $80 \%$ of the resisting forces are applied along the same boundary. In this case a thicker lithosphere at the nonrift boundaries leads to a greater resisting torque, but also to a greater possible driving torque. As a consequence, arguments based on the difference of lithosphere thickness between fast and slow spreading environments do not work with the Schouten et al. hypothesis. The absence of rotating 
microplates at slow spreading ridges thus suggest that the rift-driven model is the main driving mechanism for microplate rotation.

\section{Conclusions}

[59] 1. We have modeled microplate dynamics using finite element analysis and interpreted them using the Byerlee strength formulation, where strength increases linearly with depth. The strength of the brittle lithosphere is then proportional to the square of its thickness and is about four times greater under compression than tension.

[60] 2. The microplate rotation is driven by the outward pull of the main Pacific and Nazca plates as they diverge, as suggested by Schouten et al. [1993], and not by the underside drag, which acts as a resistance to the rotation.

[61] 3. At least $80 \%$ of the total resisting torque occurs along the northern and southern (non-rift) boundaries, and is caused by normal resistances in the vicinity of these boundaries. These resistances are tensional adjacent to the rift tips but compressive toward the rift tail ends, with compressive resistance dominating. The mantle basal drag contributes a maximum of $20 \%$ to the resisting torques, which implies that the underlying asthenosphere has a viscosity of $1 \times 10^{18} \mathrm{~Pa}$ s or less.

[62] 4. The hypothesis that the pull is principally applied to the plate by shear stress along the northern and southern boundaries [Schouten et al., 1993] can explain the compressive failure near the northern boundary.

[63] 5. The hypothesis that the pull is principally applied along the East and West Rifts can also explain the stress indicators. We have shown that a normal tension transmitted across the two rift zones, increasing linearly from near zero at the rift tails to a maximum value at the rift tips, can provide the diving torque necessary for microplate rotation. This hypothesis requires that there should be an increase in brittle plate thickness of about $1.5 \mathrm{~km}$ from rift tail to rift tip. An actual thickening greater than this is to be expected as a consequence of the slowing spreading rate toward the rift tips.

[64] 6. We suggest that microplates are mainly driven by the rift mechanism, although a combination of both driving shear along the nonrift and driving tension along the rift boundaries is to be expected.

[65] Acknowledgments. Constructive reviews by Jean Francheteau, Randall Richardson and an anonymous reviewer are much appreciated. M. Neves acknowledges the EU Training and Mobility of Researchers programme (ERBFMBICT950528) and the Gulbenkian Foundation for partial support of this work.

\section{References}

Anderson, R. N., D. W. Forsyth, P. Molnar, and J. Mammerickx, Fault plane solutions of earthquakes on the Nazca plate boundaries and the Easter plate, Earth Planet. Sci. Lett., 24, 188-202, 1974.

Barclay, A., D. R. Toomey, and S. C. Solomon, Microearthquake characteristics and crustal $\mathrm{Vp} / \mathrm{Vs}$ structure at the Mid-Atlantic Ridge, $35^{\circ} \mathrm{N}$, J. Geophys. Res., 106, 2017-2034, 2001.

Brace, W. F., and D. L. Kohlstedt, Limits on lithospheric stress imposed by laboratory experiments, J. Geophys. Res., 85, 6248-6252, 1980.

Buck, W. R., and E. M. Parmentier, Convection beneath young oceanic lithosphere: Implications for thermal structure and gravity, J. Geophys. Res., 91, 1961-1974, 1986.

Byerlee, J. D., Friction of rocks, Pure Appl. Geophys., 116, 615-626, 1978.

Chen, Y., and W. J. Morgan, A nonlinear rheology model for mid-ocean ridge axis topography, J. Geophys. Res., 95, 17,583-17,604, 1990.
Cloetingh, S., and R. Wortel, Stress in the Indo-Australian plate, Tectonophysics, 132, 49-67, 1986.

Coblentz, D. D., and R. M. Richardson, Statistical trends in the in the intraplate stress field, J. Geophys. Res., 100, 20,245-20,255, 1995.

Coblentz, D. D., and R. M. Richardson, Analysis of the South American intraplate stress field, J. Geophys. Res., 101, 8643-8657, 1996.

Cogné, J. P., J. Francheteau, V. Courtillot, R. Armijo, M. Constantin, J. Girardeau, R. Hekinian, R. Hey, D. F. Naar, and R. Searle, Large rotation of the Easter microplate as evidenced by oriented paleomagnetic samples from the ocean floor, Earth Planet. Sci. Lett., 136, 213-222, 1995.

Courtillot, V., Plaques, microplaques et déchirures lithosphériques: Une hiérarchie de structures tectoniques de l'échelle du Globe à celle du terrain, Bull. Soc. Géol. Fr., 981-984, 1980.

DeMets, C., R. G. Gordon, D. F. Argus, and S. Stein, Current plate motions, Geophys. J. Int., 101, 425-478, 1990.

Detrick, R. S., P. Buhl, E. Vera, J. Mutter, J. Orcutt, J. Madsen, and T. Brocher, Multi-channel seismic imaging of a crustal magma chamber along the East Pacific Rise, Nature, 326, 35-41, 1987.

Dziewonski, A. M., and J. H. Woodhouse, An experiment in systematic study of global seismicity: Centroid moment tensor solutions for 201 moderate and large earthquakes of 1981, J. Geophys. Res., 88, 3247$3271,1983$.

Eberle, M. A., and D. W. Forsyth, An alternative, dynamic model of the axial topographic high at fast spreading ridges, J. Geophys. Res., 103, 12,309-12,320, 1998 .

Engeln, J. F., and S. Stein, Tectonics of the Easter plate, Earth Planet. Sci. Lett., 68, 259-270, 1984.

Engeln, J. F., S. Stein, J. Werner, and R. G. Gordon, Microplate and shear zone models for oceanic spreading center reorganizations, J. Geophys. Res., 93, 2839-2856, 1988.

Forsyth, D. W., Mechanisms of earthquakes and plate motions in the East Pacific, Earth Planet. Sci. Lett., 17, 189-193, 1972.

Francheteau, J., P. Patriat, J. Segoufin, R. Armijo, M. Doucoure, A. YellesChaouche, J. Zukin, S. Calmant, D. F. Naar, and R. C. Searle, Pito and Orongo fracture zones: The northern and southern boundaries of the Easter microplate (southeast Pacific), Earth Planet. Sci. Lett., 89, 363-374, 1988.

Herron, E. M., Two small crustal plates in the South Pacific near Easter Island, Nature Phys. Sci., 240, 35-37, 1972.

Hey, R. N., D. F. Naar, M. C. Kleinrock, W. J. Phipps Morgan, E. Morales, and J.-G. Schilling, Microplate tectonics along a superfast seafloor spreading system near Easter Island, Nature, 317, 320-325, 1985.

Huang, P. Y., and S. C. Solomon, Centroid depths of mid-ocean ridge earthquakes: Dependence on spreading rate, J. Geophys. Res., 93, 13,445-13,477, 1988.

Kong, L. S. L., S. C. Solomon, and G. M. Purdy, Microearthquake characteristics of a mid-ocean ridge along-axis high, J. Geophys. Res., 97, 1659-1685, 1992.

Kruse, S. E., S. F. Tebbens, D. F. Naar, Q. Lou, and R.T. Bird, Comparison of gravity anomalies at pseudofaults, fracture zones, and nontransform discontinuities from fast to slow spreading areas, J. Geophys. Res., 105, 28,399-28,410, 2000.

Kuo, B. Y., D. W. Forsyth, and E. M. Parmentier, Flexure and thickening of the lithosphere at the East Pacific Rise, Geophys. Res. Lett., 13, 681684, 1986.

Lachenbruch, A. H., A simple mechanical model for oceanic spreading centers, J. Geophys. Res., 78, 3395-3417, 1973.

Larson, R. L., R. C. Searle, M. C. Kleinrock, H. Schouten, R. T. Bird, D. F. Naar, R. I. Rusby, E. E. Hooft, and H. Lasthiotakis, Roller-bearing tectonic evolution of the Juan Fernandez microplate, Nature, 356, 571-576, 1992.

Liggett, J. A., Fluid Mechanics, 495 pp., McGraw-Hill, New York, 1994.

Lin, J., and E. M. Parmentier, A finite amplitude necking model of rifting in brittle lithosphere, J. Geophys. Res., 95, 4909-4923, 1990.

Lin, J., G. M. Purdy, H. Schouten, J.-C. Sempere, and C. Zervas, Evidence from gravity data for focused magmatic accretion along the Mid-Atlantic Ridge, Nature, 344, 627-632, 1990.

Lonsdale, P., Structural pattern of the Galapagos microplate and evolution of the Galapagos triple junctions, J. Geophys. Res., 93, 13,551-13,574, 1988.

Luyendyk, B. P., M. J. Kamerling, and R. R. Terres, Geometric model for Neogene crustal rotations in southern California, Geol. Soc. Am. Bull., 91, 211-217, 1980.

Martinez, F., D. F. Naar, T. B. Reed IV, and R. N. Hey, Three-dimensional seaMARC II, gravity, and magnetics study of large-offset rift propagation at the Pito Rift, Easter microplate, Mar. Geophys. Res., 13, 255-285, 1991.

McKenzie, D. P., and J. A. Jackson, The relationship between strain rates, crustal thickening, paleomagnetism, finite strain and fault movements within a deforming zone, Earth Planet. Sci. Lett, 65, 182-202, 1983. 
McKenzie, D. P., and J. A. Jackson, A block model of distributed deformation by faulting, J. Geol. Soc. London, 143, 349-353, 1986.

Naar, D. F., and R. N. Hey, Recent Pacific-Easter-Nazca plate motions, in Evolution of Mid Ocean Ridges, Geophys. Monogr. Ser., vol. 57, edited by J. M. Sinton, pp. 9-30, AGU, Washington, D. C., 1989.

Naar, D. F., and R. N. Hey, Tectonic evolution of the Easter microplate, J. Geophys. Res., 96, 7961-7993, 1991.

Neumann, G. A., and D. W. Forsyth, The paradox of the axial profile: Isostatic compensation along the axis of the Mid-Atlantic Ridge, J. Geophys. Res., 98, 17,891-17,910, 1993.

Neves, M. C., Models of stress at mid-ocean ridges and their offsets, Ph.D. thesis, Univ. of Durham, Durham, U. K., 2000.

Owens, R., The morphology and tectonics of the Reykjanes Ridge, Ph.D. thesis, Univ. of Oxford, Oxford, U. K., 1996.

Pacanovsky, K. M., D. M. Davis, R. M. Richardson, and D. D. Coblentz, Intraplate stresses and plate-driving forces in the Philippine Sea plate, J. Geophys. Res., 104, 1095-1110, 1999.

Phipps Morgan, J., E. M. Parmentier, and J. Lin, Mechanisms for the origin of mid-ocean ridge axial topography: Implications for the thermal and mechanical structure of accreting plate boundaries, J. Geophys. Res., 92, 12,823-12,836, 1987.

Poliakov, A. N. B., and W. R. Buck, Mechanics of stretching elasto-plasticviscous layers: Applications to slow-spreading mid-ocean ridges, in Faulting and Magmatism at Mid-Ocean Ridges, Geophys. Monogr. Ser., vol. 106, edited by W. R. Buck et al., pp. 305-324, AGU, Washington, D. C., 1998.

Purdy, G. M., L. S. L. Kong, G. L. Christeson, and S. C. Solomon, Relationship between spreading rate and the seismic structure at mid-ocean ridges, Nature, 355, 815-817, 1992.

Richardson, R. M., and L. M. Reding, North American plate dynamics, J. Geophys. Res., 96, 12,201-12,223, 1991.

Richardson, R. M., S. C. Solomon, and N. H. Sleep, Tectonic stress in the plates, Rev. Geophys., 17, 981-1019, 1979.

Rusby, R. I., Tectonic pattern and history of the Easter microplate, based on GLORIA and other geophysical data, Ph.D. thesis, Univ. of Durham, Durham, U. K., 1992.

Rusby, R. I., and R. C. Searle, Intraplate thrusting near the Easter microplate, Geology, 21, 311-314, 1993.

Rusby, R. I., and R. C. Searle, A history of the Easter microplate, $5.25 \mathrm{Ma}$ to present, J. Geophys. Res., 100, 12,617-12,640, 1995.

Schouten, H., K. D. Klitgord, and D. G. Gallo, Edge-driven microplate kinematics, J. Geophys. Res., 98, 6689-6701, 1993.

Searle, R. C., R. I. Rusby, J. Engeln, R. N. Hey, J. Zukin, P. M. Hunter, T. P. LeBas, H.-J. Hoffman, and R. Livermore, Comprehensive sonar imaging of the Easter microplate, Nature, 341, 701-705, 1989.

Searle, R. C., R. T. Bird, R. I. Rusby, and D. F. Naar, The development of two oceanic microplates: Easter and Juan Fernandez microplates East Pacific Rise, J. Geol. Soc. London, 150, 965-976, 1993.
Searle, R. C., et al., The Reykjanes Ridge: structure and tectonics of a hotspot influenced, slow-spreading ridge, from multibeam bathymetric, gravity and magnetic investigations, Earth Planet. Sci. Lett., 160, 463478, 1998.

Shah, A. K., and W. R. Buck, Causes for axial high topography at midocean ridges and the role of crustal thermal structure, J. Geophys. Res., 106, 30,865-30,879, 2001.

Sigmundsson, F., Post-glacial rebound and asthenosphere viscosity in Iceland, Geophys. Res. Lett., 18, 1131-1134, 1991.

Sleep, N. H., and B. R. Rosendahl, Topography and tectonics of midoceanic ridge axes, J. Geophys. Res., 84, 6831-6839, 1979.

Solomon, S. C., N. H. Sleep, and R. M. Richardson, On the forces driving plate tectonics: Inferences from absolute plate velocities and intraplate stress, Geophys. J. R. Astron. Soc., 42, 769-801, 1975.

Tapponnier, P., and J. Francheteau, Necking of the lithosphere and the mechanics of slowly accreting plate boundaries, J. Geophys. Res., 83, 3955-3970, 1978.

Toomey, D. R., and G. M. Purdy, Microearthquakes beneath the median valley of the Mid-Atlantic Ridge near $23^{\circ} \mathrm{N}$ : Tomography and tectonics, J. Geophys. Res., 93, 9093-9112, 1988.

Turcotte, D. L., and G. Schubert, Geodynamics: Applications of Continuum Physics to Geological Problems, 450 pp., John Wiley, New York, 1982.

Wang, K., J. He, and E. E. Davis, Transform push, oblique subduction resistance, and intraplate stress of the Juan de Fuca plate, J. Geophys. Res., 102, 661-674, 1997.

Wang, X., and J. R. Cochran, Gravity anomalies, isostasy, and mantle flow at the East Pacific Rise crest, J. Geophys. Res., 98, 19,505-19,531, 1993.

Wolfe, C. J., et al., Microearthquake characteristics and crustal velocity structure at $29^{\circ} \mathrm{N}$ on the Mid-Atlantic Ridge: The architecture of a slow-spreading segment, J. Geophys. Res., 100, 24,449-24,472, 1995.

Wortel, M. J. R., M. J. N. Remkes, R. Govers, S. A. P. L. Cloetingh, and P. T. Meijer, Dynamics of the lithosphere and the intraplate stress field, Philos. Trans. R. Soc. London, Ser. A, 337, 111-126, 1991.

Yelles-Chaouche, A., J. Francheteau, and P. Patriat, Evolution of the Juan Fernandez microplate during the last three million years, Earth Planet. Sci. Lett., 86, 286-296, 1987.

Zoback, M. L., First- and second-order patterns of stress in the lithosphere: The World Stress Map Project, J. Geophys. Res., 97, 11,703-11,728, 1992.

M. H. P. Bott and R. C. Searle, Department of Geological Sciences, University of Durham, South Road, Durham, DH1 3LE, UK.

M. C. Neves, CIMA, FCMA, Universidade do Algarve, Campus de Gambelas, 8000 Faro, Portugal. (mcneves@ualg.pt) 